leading to an excess of transmitter at postsynaptic receptor sites. Signs and symptoms of acute cocaine intoxication include agitation, tachycardia, palpitations, hypertension, hyperthermia, confusion, disorientation, and hallucinations. Massive doses can result in arrhythmias, seizures, and metabolic acidosis, which is often fatal.

Medical treatment is focused on treating complications as they arise. Propranolol 1 $\mathrm{mg} / \mathrm{min}$ intravenously may specifically antagonise the sympathomimetic effects of cocaine. Diazepam $2.5-5.0 \mathrm{mg}$ or high-dose chlorpro-

1 Gherardi R, Marc B, Alberti X, Baud F, Diamant-Berger O. A cocaine body packer with normal abdominal plain radiograms, value of drug detection in urine and contrast study of the bowel. Am F Forensic Med Pathol 1990;11:154-7.

2 Mebanex C, De Vito J. Cocaine intoxication, a unique case. f Fla Med Assoc 1975;62:19-20. 3 Beck NE, Hale JE. Cocaine 'body packers.' Br $\mathcal{F}$ Surg 1993;
12:1513-6. mazine have been used to prevent seizures. Dantrolene $1 \mathrm{mg} / \mathrm{kg}$ intravenously over $10-15$ min has variable success in treating refractory hyperthermia. Once the patient is stabilised, surgery may be indicated to prevent rupture of any remaining packets.

\section{Final diagnosis}

Intracorporeal cocaine-filled packets in a 'body-packer'

Keywords: cocaine; drug smuggling; body-packer

4 Lancashire MJR, Legg PK, Lowe M, Davidson SM, Ellis $\mathrm{BW}$. Surgical aspects of international drug smuggling. $B M F$ 1988;296:1035-7.

5 Trent MS, Kim U. Cocaine packet ingestion, surgical or medical management? Arch Surg 1987;122:1179-81.

\title{
An 88-year-old woman with tetraparesis after a fall
}

\author{
B Klemenz, P A Banaszkiewicz, F W Smith
}

An 88-year-old woman with a medical history of drug-controlled hypertension and type II diabetes mellitus was admitted to hospital after a fall headlong downstairs at home. She sustained a blow to the right temporal region of her skull, but did not lose consciousness. She was immediately paralysed after her fall. On admission to hospital the patient complained of weakness and an 'odd feeling' in both her arms and legs but denied any neck pain.

On examination she was found to be fully conscious with spontaneous breathing. A minor contusion was present over her right temple. The upper extremities demonstrated grade $3 \mathrm{MRC}$ power with diminished triceps and biceps jerks. A total flaccid paralysis was present in her right leg with grade 3 MRC power in her left leg. No knee or ankle jerks were present in either leg. The left plantar response was down-going, the right equivocal. She had no sensation below shoulder level although joint position sense in the toes was maintained. Peri-anal sensation and rectal tone were preserved It was necessary to insert an indwelling urinary catheter for urinary retention.

Initial treatment consisted of immobilisation in a hard collar. Skull X-rays were taken in the accident and emergency department which were normal. After consultation with the radiology department it was decided to proceed straight to an emergency magnetic resonance imaging (MRI) scan of the cervical spine (figure), rather than perform cervical spine X-rays.

\section{Woodend Hospital, Eday Road, Aberdeen AB15 6LS, UK Department of Geriatric Medicine B Klemenz MRI Centre \\ F W Smith}

Department of Orthopaedic Surgery, University of Aberdeen Medical School, Aberdeen, UK

P A Banaszkiewicz

Correspondence to $\mathrm{B}$ Klemenz, Royal Victoria Hospital of Edinburgh, Department of Care of the Elderly, 13 Craigleith Road, Edinburgh EH4 2DN, UK

Accepted 20 August 1997

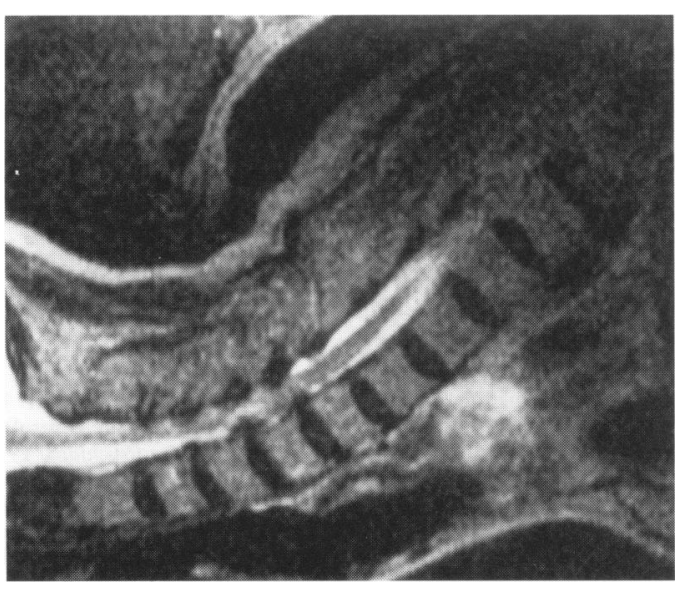

\section{Questions}

1 What is the most probable diagnosis?

2 What does the MRI scan show?

3 What is the treatment of choice in this case? 
Answers

QUESTION 1

The diagnosis is an acute central cord syndrome.

QUESTION 2

The MRI scan was performed using T1- and T2- weighted sequences in sagittal and transverse sections. It demonstrates severe narrowing of the spinal canal due to spondylitic changes which are most marked at the $C 4 / 5$ and $\mathrm{C} 5 / 6$ levels. At both levels there is severe impingement upon the cervical cord, which shows evidence of ischaemic change due to the compression. There is no evidence of a vertebral body fracture or of significant invertebral disc disease. The spinal stenosis is causes by large facet joints and osteophyte formation.

MRI is a good diagnostic tool and prognostic indicator in the assessment of spinal injuries. The MRI scan can differentiate between spinal cord oedema, ${ }^{1}$ haemorrhage and transection. The images correlate strongly with the severity of the neurological deficit and the degree of subsequent recovery. An incidental thyroid adenoma is also apparent in the sagittal view.

\section{QUESTION 3}

The acute central cord syndrome can present with severe hypotension secondary to spinal cord mediated neurogenic shock which requires supportive treatment. Steroids have been shown to be beneficial in the first eight hours, which may result in significant improvement in motor and sensory function. Methyl prednisolone may act through mechanisms which improve perfusion in the microvasculature circulation with reduction in lipid peroxidation and protein degradation. ${ }^{2}{ }^{3}$ New experimental treatment approaches are aiming at free radical scavengers, opioid receptor antagonists, including thyrotropin-receptor hormone, calcium channel blockers, cycloxygenase inhibitors, serotonin antagonist and others. Early management consists of general supportive measures with particular attention to bladder and skin care. If the functional deficit is severe, transfer to a specialised spinal rehabilitational unit may be indicated.

Surgery is generally not indicated unless there has been an underlying fracture causing cord compression or spinal instability. There is substantial risk of further neurological damage along with an increased anaesthetic mortality risk in elderly patients. Treatment would consist of wearing a hard collar to immobilise the cervical spine for several weeks.

\section{Discussion}

The syndrome most typically occurs following a hyperextension injury in elderly patients with pre-existing cervical spondylosis. The amount of trauma may be minimal. The spinal cord is pinched between the vertebral body anteriorly and the buckled ligamentum flavum posteriorly. Occasionally it may present in younger people who have had a severe hyperextension injury with or without a fracture of the cervical spine. It is thought to be caused by an expanding haematoma or oedema forming in the central cord. The condition is characterised by disproportionately more motor impairment of the upper than of the lower extremities, by bladder dysfunction, usually by urinary retention, and by varying degrees of sensory loss below the level of the lesion.

It can be quite variable in presentation and in recovery. Mild cases may present with a burning sensation in the upper limbs while severe cases, with caudal or cephalic extension of the lesion, may result in complete tetraplegia or death. ${ }^{4}$ The amount of recovery depends on the degree of oedema present that resolves and the amount of neurological tissue destruction.

Prognosis for this syndrome is fair; $50-70 \%$ of patients can be expected to have progressive return of motor and sensory power to the lower extremities and trunk, but they have poor recovery of hand function. ${ }^{5}$ They are able to regain bladder and bowel function and walk with a spastic gait.

The pattern of clinical presentation is directly related to the cross-sectional anatomy of the spinal cord. Lower extremity and sacral tracts of the cortical and spinothalamic tracts in the white matter are laterally placed and may be relatively spared. In cases in which they are affected these areas tend to recover first. Damage to the central grey matter, which affects the upper extremities, is more severe and irreversible.

This was an unusual presentation in that some of the neurological features were atypical. Classically, an acute central cord syndrome presents with a severe flaccid lower motor neuron paralysis of the fingers, hands, and arms, and an upper motor neuron spastic paralysis of the trunk and extremities.

\section{Final diagnosis}

Acute central cord syndrome.

Keywords: acute central cord syndrome; paralysis; cervical spondylosis
1 O'Beirne J, Cassidy N, Raza K, Walsh M, Stack J, Murray P. Role of magnetic resonance imaging in the assessment of spinal injuries. Injury 1993;24:149-54.

2 Tator CH.Update on the pathophysiology and pathology of acute spinal cord injury. Brain Pathol 1995;4:407-13.

3 Bracken MB, Shepard MJ, Collins WF, et al. A randomized, controlled trial of methylprednisolone or naloxone in the treatment of acute spinal cord injury - results of the second National Acute Spinal Cord Injury Study. $N$ Engl $\mathcal{F} \mathrm{Med}$ 1990;20:1405-11.
4 Richard C, Schnneider J, Thompson M, Bebin J. The syndrome of acute central cervical spinal cord injury. $\mathscr{F} \mathrm{Neu}$ rol Neurosurg Psychiatry 1958;21:216-27.

5 Stauffer ES, MacMillan M. Fractures and dislocations of the cervical spine. In: Rockwood CA, Green DP, Buchholz RW, Heckman JD, eds. Fractures in adults, vol 2. Lippincott Raven, 1996; pp 1473-528. 